\title{
Monstros Sagrados e Ciberculturais: H. P. Lovecraft e sua mitologia na cultura contemporânea ${ }^{1}$
}

Yuri Garcial

I - UERJ

Rio de Janeiro (RJ), Brasil

Resumo: O presente artigo procura analisar a relação entre horror e religião na obra de H. P. Lovecraft e suas articulações por meio de outras mídias e no campo da cibercultura. O autor, que não gozava de muito prestígio no passado, tem penetrado cada vez mais no atual cenário tanto em âmbitos considerados eruditos quanto em âmbitos considerados massivos ou populares. Desse modo, ao investigar as razões desse surpreendente renascimento de Lovecraft na esfera da chamada alta cultura (literatura, artes, filosofia), buscaremos ao mesmo tempo as motivações de seu interesse no âmbito da cultura popular e midiática e estudando as formas e apropriações como seus temas, ideias ou mesmo obras foram absorvidos pelos meios de comunicação contemporâneos.

Palavras-chave: Lovecraft; cibercultura; horror; religião.

Abstract: Sacred and Cybercultural Monsters: H. P. Lovecraft and his mythology in contemporary culture - This article aims to analyze the relation between horror and religion in the work of H. P. Lovecraft and its articulations through other media and in the field of cyberculture. The author, who has not enjoyed much prestige in the past, has increasingly penetrated the current scene in the fields considered erudite as much as the massive or popular scopes. Thus, in investigating the reasons for this surprising rebirth of Lovecraft in the sphere of so-called high culture (literature, arts, philosophy), we are at the same time seeking the motivations of his interest in popular and media culture and studying the forms and appropriations which his themes, ideas or even works were absorbed by the contemporary media.

Key-words: Lovecraft; cyberculture; horror; religion.

1 Uma versão inicial deste artigo foi apresentada no IV Encontro Regional Sudeste de História da Mídia Alcar Sudeste, 2016. 


\section{Introdução}

Em 20 de agosto de 1890, na cidade de Providence, nasce Howard Philips Lovecraft. Enquanto vivo, e também por um longo tempo após sua morte, foi encarado como um autor menor pela crítica literária e "seus leitores se resumiam, além do seu círculo de amigos - que Lovecraft mantinha por meio de um dos epistolários mais impressioanantes de que se tem notícia -, aos consumidores de Weird Tales e outras publicações baratas." (MAPA In: LOVECRAFT, 2017, p. 12) Morreu em março de 1937 e, embora não tenha sido um autor de grande repercussão ou sucesso em vida, possuía fiéis seguidores do seu trabalho, que contribuíram para fazer algumas de suas últimas obras chegarem às prensas. Embora suas histórias tenham alcançado certo público de nicho após sua morte e tenham gozado de certo prestigio na cultura de massa, Lovecraft experimentou, nos últimos anos, uma espécie de renascença cultural, que começou a legitimá-lo como artista digno de figurar no cânon da alta literatura, além de ser considerado um dos mestres do gênero do horror. Grande parte desse êxito se deve ao escritor e ensaísta Michel Houellebecq que defende o valor literário de sua obra, principalmente em seu livro, publicado pela primeira vez em 1991, H. P. Lovecraft: Contre le monde, contre la vie. ${ }^{2}$

Além do aspecto pessoal do livro, já que Houellebecq declara sua leitura apaixonada pelos contos lovecraftianos, ressalta ali a importância do autor como escritor e pensador. Contudo, em 1980, a filosofia já se apropriava de Lovecraft por meio de Deleuze e Guattari. No final do primeiro volume de Mil Platôs: capitalismo e esquizofrenia (1995), os autores citam um trecho do conto Through the Gates of the Silver Key $(1933)^{3}$, que consideram a maior obra-prima de Lovecraft. No oitavo capítulo do quarto volume (1997), "DevirIntenso, Devir-Animal, Devir-Imperceptível", Lovecraft é um nome recorrente. O aspecto outsider do autor na literatura é destacado, assim como a multiplicidade de sua obra. No pequeno texto A literatura e a vida, componente de Crítica e Clínica (1997), Deleuze escreve sobre a literatura, a linguagem e o ato de escrever:

Escrever é um caso de devir, sempre inacabado, sempre em via de fazer-se, e que extravasa qualquer matéria vivível ou vivida. É um processo, ou seja, uma passagem de Vida que atravessa o vivível e o vivido. A escrita é inseparável do devir: ao escrever, estamos num devimos-mulher, num devimos-animal ou vegetal, num devir-molécula, até num devir-imperceptível. Estes devires encadeiam-se uns aos outros segundo uma linhagem particular, como num romance de Le Clézio, ou então coexistem em todos os níveis, segundo portas, limiares e zonas que compõem o universo inteiro, como na pujante obra de Lovecraft (p. 11).

Os esforços de S. T. Joshi (considerado o maior especialista no autor) de publicar diversos escritos de Lovecraft, como contos, ensaios e poemas, e colaborar com importantes

2 Para este trabalho, usamos a versão em inglês de 2005.

3 Escrito em parceria com E. Hoffman Price, o conto é uma continuação de The Silver Key (1926), de Lovecraft. 
pesquisas e biografias do autor como, A Dreamer and a Visionary: H. P. Lovecraft in his time (2001) e I Am Providence: The Life and Times of H. P. Lovecraft (2010), são essenciais para o desenvolvimento do crescente estudo sobre o autor no âmbito acadêmico. Mais recentemente, no Brasil, Erick Felinto (2015) apresenta um breve levantamento sobre essa utilização de Lovecraft, apontando sua retomada na cultura erudita, principalmente em uma apropriação massiva na filosofia em temas como a metafísica, o pós-humanismo e a complexidade do nosso universo. Todavia, a apropriação cultural de Lovecraft não se dá apenas na academia. Atualmente, não apenas encontramos suas obras adaptadas para diversas mídias como cinema, histórias em quadrinho e videogames, mas também é possível detectar a penetração de elementos da sua complexa mitologia em ambientes midiáticos.

Para pensarmos nessa relação entre suas obras e seu diálogo com outras mídias, podemos compreender o fenômeno da Cauda Longa (ANDERSON, 2006) como um importante agente ao possibilitar um crescimento da produção de produtos considerados mais de nicho, assim como também podemos evocar o termo Remediation cunhado por Jay Bolter e Richard Grusin (2000) para refletir sobre as novas versões baseadas nos escritos de Lovecraft e de sua mitologia. O livro de Bolter e Grusin possui o subtítulo Understanding New Media reforçando a ideia mcLuhaniana de que as novas mídias trazem elementos (não só em sua gramática e linguagem como também nos produtos) de mídias anteriores ao prestar uma homenagem ao seu mais famoso livro Understanding Media ${ }^{4}$. Vinícius Andrade Pereira destaca que "[...] um meio porta um outro meio no seu interior, como maneira de se apresentar e se traduzir para um usuário" (PEREIRA, 2011, p. 142). Ao discutir a relação entre ambas as obras no capítulo 7, Pereira refere-se mais à questão gramatical, entretanto uma parte da obra de Bolter e Grusin é destinada aos conteúdos, tomando como exemplo uma onda de transposições fílmicas de obras de Jane Austin já a partir da década de 90 .

Seria assim a massiva aparição de elementos lovecraftianos em nossa cultura resolvida por meio da ideia de remediação? Embora sirva de uma ancoragem teórica inicial, faz-se necessário apontar aqui uma complexidade maior. Lovecraft produziu uma profunda reformulação da noção tradicional de mito, elaborando um panteão de deuses monstruosos inteiramente indiferentes ao homem (Cf. LUDUEÑA, 2013). Esse conjunto de mitos e narrativas que, além de tudo, poderia ser qualificado como uma espécie de trabalho colaborativo nos moldes da cultura digital (avant la lettre) recebeu de August Derleth (um escritor e fiel seguidor com quem o autor trocava correspondências, e que desenvolvia contos a partir das criações lovecraftianas) a designação de Cthulhu Mythos. "Criando suas visões, então, Lovecraft estabeleceu as lendas de Cthulhu, uma de suas mais famosas e mais populares criações imaginárias." (KUTRIEH, 1985, p. 41).

Dessa forma, o autor traz a ideia de mito na modernidade com uma nova face, a do horror inumano, criando seres e universos que ultrapassam os limites da racionalidade.

4 Para esse trabalho usamos a versão em português de2007. 
Seu mundo imaginário representa o ser humano como criatura abandonada em um cosmos indiferente à sua existência, dando forma a uma peculiar mitologia não (ou mesmo anti) antropocêntrica. Espécies alienígenas muito superiores teriam dominado a Terra em um passado remoto e aguardam adormecidas seu retorno em um futuro apocalíptico. Dessa forma, o autor nos apresenta um conceito de divindade que prescinde dos homens e habita outra(s) dimensão(ões), possuindo noções de tempo e espaço muito além da capacidade de compreensão humana.

O Cthulhu Mythos aponta um destino cruel para a humanidade; contudo, sublinha um paradoxo ao pensarmos como essa mitologia consegue se estabelecer de forma tão pregnante na cultura contemporânea. Quanto mais aterrador e anti-humano é determinado aspecto do mito, mais nos sentimos atraídos por ele. E essa atração não se dá somente em um plano da curiosidade sobre sua obra, mas também por meio da propagação e contínua reelaboração dela.

Ou seja, mesmo percebendo que o destino da humanidade para Lovecraft é apocalíptico e que nos encontramos em uma posição inferior aos poderosos habitantes extraterrestres do planeta (The Old Ones), nos sentimos atraídos por essa concepção. Não satisfeitos, reproduzimos essa mitologia dando vida a essa ficção e criando novos produtos midiáticos baseados no imaginário lovecraftiano. "A discursificação, presentificação e aceitação dos monstros na atualidade parecem apontar não para uma crise no conceito de monstro, mas para as angústias e inquietações a respeito de nossa própria humanidade." (REGIS, 1999, p. 10)

Desse modo, ao abordarmos essa relação de permanência, devoção e reprodução do mito de Lovecraft, nos deparamos com múltiplas questões que valem ser destacadas. Inicialmente, percebemos que, após sua morte, inaugura-se um processo que muito se assemelha às fan-fictions tão popularmente manifestadas na contemporaneidade. Aqui, nos deparamos com um novo paradoxo. Em Lovecraft, o fenômeno cult ${ }^{5}$ atinge toda sua potência, manifestando-se como uma adoração divina do autor e do tratamento de sua obra como escritura sagrada, porém essa obra sagrada é continuada por seus seguidores que tentam superar a original (num processo que talvez até mesmo extrapole os mecanismos da "angústia da influência", de Harold Bloom6).

\section{Cibercultura, horror e religião}

Lovecraft desenvolve uma mitologia complexa que se espalha massivamente por diversos âmbitos da nossa cultura. A cibercultura é um estudo interdisciplinar que promove perspectivas que podem ser relacionadas com horror, religião e, como pretendemos

5 O termo possui uma significação muito ampla, porém neste estudo adotaremos a obra de JANCOVICH et al. (2003) como referência.

6 A "angústia da influência" é uma teoria desenvolvida pelo crítico literário Harold Bloom, segundo o qual todo autor "tardio" (belated) sente o peso de seus precursores e assim se vê obrigado a confrontar-se com sua obra "deslendo-a" (misreading) e reelaborando-a. Para mais detalhes ver: Bloom, 2002. 
demonstrar aqui, com o escritor de Providence. O ambiente digital contemporâneo é permeado por referências lovecraftianas em grande escala, e alguns autores do campo podem nos revelar o quanto sua mitologia é capaz de ser compreendida pelas teorias apresentadas.

Bruno Latour (2012) apresenta a Teoria Ator-Rede que permite abordar qualquer fenômeno em sua complexidade por meio de um pensamento em rede ${ }^{7}$ em que os objetos passam a ter uma importância maior. Gilbert Simondon (1980) que, embora não seja creditado, parece ser uma clara inspiração para Latour ao mostrar a relação intrínseca entre natureza, homem e técnica. Sua ideia de individuação aponta para o processo pelo qual uma coisa se individualiza de um fundo comum. Ou seja, o indivíduo nunca pode estar congelado, pois nele há forças individualizantes e transindividualizantes criando um conflito energético. Já no título do livro de Simondon, percebemos o protagonismo dos objetos técnicos na cultura, posição que, posteriormente, vemos Latour adotando com suas propostas metodológicas.

Lovecraft mostra a complexidade do universo ao nos alertar para a nossa insignificância diante dele e destaca a importância dos objetos em seus contos (nesse caso, podemos apontar as criações de grimórios diversos, sendo o Necronomicon o mais famoso, como os exemplos mais óbvios). Ainda assim, como pensar em religião e horror se articulando com cibercultura, ou até entre si? Para chegarmos a esse ponto, precisamos compreender o que é o horror e de onde surge.

Podemos encontrar algumas das primeiras manifestações do horror no horizonte da religião, bem como na mitologia, superstições e folclores. Todavia, é por meio da literatura que ele se estabelece e se normatiza como um gênero, com o surgimento do gótico em um período marcado pela dualidade entre iluminismo e religião (Cf. CARROLL, 1990, p. 54-56). O gótico formalizou e padronizou a expressão de emoções primais em um gênero literário. Contudo, essa formalização trazida pela literatura também faz com que o horror possua suas próprias características e deixe de ser apenas um aspecto percebido dentro da mitologia.

De certa forma, nesse momento podemos averiguar certa independência por parte do horror. Embora ainda possua uma ligação explícita com a religião (ou a dimensão do sobrenatural), agora passa a utilizá-la em suas histórias, não sendo mais unicamente um aspecto do pensamento mítico. "Oscilando entre os pólos da realidade e da fantasia, ele opera, na verdade, na fronteira entre as miudezas da vida cotidiana e o território nebuloso do mito." (VASCONCELOS, 2002, p. 133)

Essa ruptura inicial principia um afastamento que vai se acentuando com o tempo. Passamos a atribuir o horror às maquinas que se rebelam contra seus criadores (tema que podemos ver com frequência também na cibercultura), aos fenômenos da natureza e aos assassinos que são tão humanos como nós. O horror passa a habitar nosso cotidiano disfarçado de normalidade.

7 Vale destacar que, embora a Teoria Ator-Rede seja uma ideia de Latour, a sociologia já trabalhava o conceito de rede focando nas relações sociais e no indivíduo desde a década de 1950 com autores como Barnes, Mitchell e outros, até a chamada Escola de Nova York na década de 1990. Para mais detalhes ver: ENNE (2004); MITCHELL (1974); MISCHE (2011). 
Podemos analisar essa questão por meio das representações dos diferentes imaginários culturais. O horror nasce (na mitologia, folclore e contos) em um homem dominado pela visão teocêntrica, utilizando explicações religiosas para todo mal que encontra.

Como se sabe, nas primeiras sociedades humanas vigorava o pensamento mítico que explica a origem do mundo e o funcionamento da natureza com base em uma ordem divina, misteriosa e sobrenatural. Sendo um discurso de fundação, o saber mítico organiza o conhecimento como uma verdade absoluta e inquestionável. (REGIS; MESSIAS In. REGIS et al. (Org.), 2012, p.26)

Com o passar do tempo, a ascensão do humanismo liberal e das ciências questionadoras da existência divina, passamos a recorrer mais a fundamentações biológicas e psicológicas nas tramas ${ }^{8}$, de forma que a religião começou a fazer parte apenas de uma das quatro explicações mais utilizadas no horror: religião, natureza, tecnologia e psicologia.

Lovecraft surge em um momento altamente sintomático, marcado pela modernidade que tenta expurgar os últimos vetores míticos do pensamento. Tendo nascido no final do século XIX e começado a produzir seus contos no início do século XX, o autor retorna com as noções de mito em um período marcado por inovações tecnológicas como a fotografia, o cinema e as histórias em quadrinhos ${ }^{9}$ que, mais tarde, se apropriariam de elementos de suas narrativas, propagando sua mitologia na cultura midiática.

Atualmente, o Cthulhu Mythos se encontra espalhado por nossa cultura das mais diversas formas. O grimório Necronomicon, criado pelo autor, além de utilizado em diversas outras histórias como um livro proibido capaz de despertar o mal, é tratado por alguns como um artefato que realmente existe e é visto em filmes como a trilogia de Sam Raimi, Evil Dead (1981), Evil Dead II (1987), Army of Darkness (1992) e a série Ash vs Evil Dead (2015), entre outros. A cidade fictícia Arkham em que grande parte de suas histórias se passam é referenciada como o Asilo Arkham encontrado em Gotham City, cidade do universo de quadrinhos da DC. A influência de seus temas se encontra presente em filmes de diversos diretores como John Carpenter, Guillermo Del Toro e autores como Stephen King ${ }^{10}$. Diversas apropriações amadoras e profissionais de sua mitologia para contar histórias ou até criar jogos povoam nossa cultura desde fan-fictions até maiores produções com alto orçamento. Gabriela Birnfeld Kurtz (2017) faz um breve levantamento das aparições de

8 Podemos ver a racionalidade Ocidental desempenhando um papel fundamental nesse processo. "A história da civilização no Ocidente é a história de um apagamento da figura de Deus, não apenas no sentido da interdição bíblica à produção de imagens, mas do desaparecimento progressivo do contato com o divino, dos laços e sinais que apontavam sua presença no mundo." (FELINTO, 2006, p. 69).

9 Vale ressaltar aqui que, desde seu surgimento na década em que Lovecraft nascera (1890), as histórias em quadrinhos ainda eram, em geral, comic strips, encontradas dentro do jornal. A década de 1930 marca o momento em que surgem as comic books, uma versão encadernada e comercializada como revista, se tornando independente de outros suportes como o jornal para o seu consumo. Para mais detalhes ver: MESSIAS, 2012, p. 39-41.

10 Em diversas entrevistas Stephen King revela que Lovecraft é um grande inspirador e o maior escritor de horror de todos os tempos; John Carpenter e Guillermo del Toro ainda vão mais longe, tendo participado do documentário Lovecraft: Fear of the Unknown de 2008 como grandes conhecedores da obra e vida do autor. 
sua mais famosa divindade, o monstro Cthulhu, no Facebook. Em um levantamento feito em fevereiro de 2017, descobriu que até aquele momento havia:

[...] mais de 100 páginas ligadas à palavra-chave Cthulhu no Facebook -na com maior audiência, que também é o ambiente sobre o qual será realizada a análise, a página homônima possui 327.639 fãs, e a mais relevante dentre as criaturas criadas por Lovecraft. (BIRNFELD KURTZ, 2017, p. 442).

Cthulhu possui uma popularidade incrível aparecendo em diversas imagens em forma de brincadeira, reelaborações e tentativas de reproduções fiéis. Dentre elas, vale destacar rapidamente as ocorridas normalmente durante eleições presidenciais americanas: "Cthulhu para presidente: por que escolher o menos mal?". ${ }^{11}$ Ou seja, além de a literatura lovecraftiana povoar a cultura pop atravessando diferentes plataformas e veículos, a mitologia criada pelo autor se faz presente na forma de citações e reelaborações, bem ao gosto de uma estética pós-moderna.

Lovecraft não elabora uma religiosidade propriamente dita, e sim uma noção de sobrenatural centrada na figura do monstro. A palavra vem do latim monstrum que seria algo como aberração. Todavia, investigando mais a fundo encontramos o verbo monstrare que significaria indicar, apontar, ou procurando uma palavra mais simples, cotidiana e similar, mostrar. Então, o monstro seria o que se mostra, ou aberração que se mostra talvez seja mais próximo de um sentido mais específico.

A figura da monstruosidade exerceu uma função simbólica fundamental. Perturbando os sentidos, especificamente a visão, o monstro foi pensado como uma aberração, uma folia do corpo, introduzindo, como oposição lógica, a crença na necessidade da existência da "normalidade" humana, do corpo "lógico." (TUCHERMAN, 1999, p. 79).

Partindo da etimologia da palavra monstro, encontramos o ato de se revelar presente nesse ser. No contexto do pensamento medieval, por exemplo, "os monstros são manifestações físicas, palpáveis, corpóreas de atos pecaminosos" (FELINTO; SANTAELLA, 2012, p. 85) ou então materializações do poder ilimitado de Deus (mirabilia). Dessa forma, o aspecto material é altamente essencial. Ao atribuirmos o caráter divino aos monstros, trazemos a crença e a fé presentes na religião para um plano do tangível. O espantoso em Lovecraft é material, rompe a barreira entre o fantástico e o explicável. A dualidade entre Logos e Mythos, razão e crença, não existe em sua obra. A mitologia é explicada e comprovada em suas histórias que costumam centrar-se em uma narração em primeira pessoa de um indivíduo ligado á razão (cientista, historiador etc.), descobrindo o horror sobrenatural por meio de investigações.

11 "Cthulhu for president: why vote for lesser evil?" 
O que cada um dos protagonistas lovecraftianos faz é desbravar fronteiras. Inicialmente físicas, ao se deslocarem até lugares distantes e desabitados e o explorarem e, em um segundo momento, culturais, ao se depararem com criaturas até então desconhecidas e que transgridem muito do que se conhece a respeito da natureza e seu funcionamento. Após tais descobertas, o que esses personagens fazem é retornar imediatamente à segurança de suas cidades e deixar esses locais que exploraram novamente abandonados. O choque causado pelas novidades que encontram causa o efeito imediato de necessidade de um retorno à ordem. Apesar dessa tentativa, suas consciências já não são mais as mesmas, pois tornaram-se diversas pelo contato com a diferença. (SCOTUZZI; ROSSI, 2017, p. 93-94).

Lovecraft retoma a ideia do desconhecido habitando o mesmo plano que nós, apontando a nossa cegueira, a nossa ignorância sobre a verdade como fundamental para nossa felicidade e sanidade. Não é casual o fato de que vários seres da mitologia de Cthulhu habitem as profundezas aquáticas. Podemos perceber uma longa tradição de seres míticos aquáticos como o Leviatã, o monstro do lago Ness, o Cracken e outros. Os mares e oceanos se mostravam como uma enorme porção do planeta que era inexplorada pela humanidade e em que figuravam temores e superstições do homem.

O escritor de Providence traz a possibilidade de um novo mundo, um mundo não humano que nos apresenta uma alteridade radical. Sua mitologia nos envolve de forma que consumimos seus produtos mesmo sem notar. A franquia Alien possui uma premissa muito similar à ideia proposta pelo Cthulhu Mythos com seres de outros planetas superiores à humanidade sendo os responsáveis por nossa criação. H. R. Giger, o responsável pela criação estética dos monstros e cenários do filme, diz que baseou suas criações em Lovecraft e chegou a publicar um livro de pinturas e litografias chamado Necronomicon $(1992)^{12}$. O filme de 2012, de Ridley Scott, Prometheus (2012) seria uma preque/13 para Alien, o Oitavo Passageiro (1979), do mesmo diretor. A ideia em Prometheus deixa mais explícita a influência da mitologia de Lovecraft e chegou a desanimar o diretor Guillermo Del Toro a dar continuidade ao seu antigo projeto de adaptar o conto At the Mountains of Madness para o cinema ${ }^{14}$.

12 Para mais detalhes ver: Lúcio Reis Filho (2017) e Fernando Ticon e Ramon Mapa (2017). Além de ambos os textos trazerem informações sobre o artista H. R. Giger e sua relação com Lovecraft, apresentam bons exemplos de apropriações da obra lovecraftiana em nossa cultura.

13 Utilizamos aqui a palavra "prequel" em inglês devido a uma ausência de tradução que possua o mesmo significado e seja usado da mesma forma no vocabulário cotidiano no português. A palavra "prequela" serviria inicialmente, porém é utilizada no português lusitano e não possui registro no site da Academia Brasileira de Letras (site: http://www.academia.org.br/abl/cgi/cgilua.exe/sys/start.htm?sid=23). Outras possibilidades seriam as palavras "prólogo", "prelúdio", "prefácio", "preliminar", "preâmbulo" e "proêmio", contudo são frequentemente utilizadas na música, teatro, literatura e esportes, ficando marcadas pelas suas utilizações mais comuns. "Introdução", embora mais simples, não abarca exatamente a ideia necessária.

14 Ver: http://ew.com/article/2012/06/10/prometheus-ridley-scott-guillermo-del-toro-lovecraft/ e http://collider. com/at-the-mountains-of-madness-prometheus/ 
Após o longo processo de secularização que afastou a figura do divino do núcleo narrativo da cultura ocidental, a emergência das tecnologias midiáticas (em especial as tecnologias digitais) abriram um novo espaço em que os antigos deuses e valores religiosos poderiam habitar. Seguindo uma já respeitável tradição de pesquisa, Erick Felinto dedica seu livro A religião das máquinas (2005) a pensar o imaginário da cibercultura, em diversos ensaios que destacam a presença de uma nova "mitologia digital" surgindo na internet.

\begin{abstract}
A abundância de metáforas, comparações, argumentos e analogias de origem religiosa nos discursos promotores da cibercultura denuncia o pacto que ali se trava entre uma certa espécie de ciência (tecnociência) e uma certa forma de religiosidade (tecnognóstica). O próprio fato de que o discurso sobre tais tecnologias esteja dominado pelo paradigma metafórico é indicativo de uma sobreposição do imaginário ao racional. (FELINTO, 2005, p. 94).
\end{abstract}

Enquanto o tema da religião perde sua força nos horizontes da ciência ou da filosofia, os ambientes midiáticos contemporâneos abrem suas portas para esse tipo de estudo. Lovecraft, como uma figura de extrema proliferação nos mais diversos meios de comunicação, nos presenteia com suas figuras monstruosas do horror na cibercultura e na religião.

\title{
Considerações finais
}

A relação entre horror e religião é explorada por meio da figura do monstro na obra Religion and its Monsters (2002), de Timothy K. Beal. Segundo o autor, o horror se encontra na religião, assim como a religião no horror. Seu intuito não é descobrir o que significam os termos acima, nem procurar motivos que expliquem essa ligação, mas apontar pontos de convergência entre ambos. Lovecraft, por sua vez, em seu ensaio Supernatural Horror in Literature (1927), afirma que "o conto de horror é tão antigo quanto o próprio pensamento e a fala humanos." Vale assinalar que sua noção de horror está totalmente vinculada à ideia de sobrenatural, como se pode depreender da seguinte passagem:

O verdadeiro conto de horror possui algo mais do que um assassinato secreto, ossos sangrentos, ou uma forma coberta de lençol tinindo correntes conforme a regra. Uma certa atmosfera de ofegante e inexplicável receio de externo, forças desconhecidas devem estar presentes; e deve haver uma dica, expressada com uma seriedade e mau agouro se tornando seu sujeito, das mais terríveis concepções do cérebro humano - uma suspensão particular e maligna ou derrota daquelas leis fixas da Natureza que são nossas únicas ressalvas contra os assaltos do caos e os demônios do insondável espaço. (LOVECRAFT, 1927).

Pela perspectiva de Lovecraft, pensamos o horror como os limites do homem. Não apenas o medo, mas também o desconhecido que, em Lovecraft, surge por meio de 
sua mitologia que traz uma religiosidade apresentando sua face monstruosa. Eugene Thacker (2011) evoca o pensamento do teólogo Rudolph Otto, que examina a experiência religiosa por meio do conceito de numinoso ${ }^{15}$ como "experiência limite do humano confrontando o mundo como absolutamente não-humano" (THACKER,2011,p. 92), fazendo assim a ligação com o horror.

Para Otto, o numinoso descreve uma experiência contraditória do horror e do espanto que está encapsulada em sua expressão, mysterium tremendum. Tanto o mistério quanto a "prevalência" dos tremores ou terror entram na teoria da experiência religiosa de Otto. (THACKER,2011, p. 93).

Desse modo, a ligação do horror com a religião se daria por meio do "monstruoso" e do "desconhecido", que é exatamente o que Lovecraft nos apresenta. Podemos pensar, inicialmente, em seus contos fundados sobre três ideias básicas: o sobrenatural, o desconhecido e uma criação de sensações e ambiências ${ }^{16}$ que provoquem o medo.

Minha razão para escrever histórias é dar a mim mesmo a satisfação de visualizar mais claramente e detalhadamente e estável as vagas, indefinidas e fragmentadas impressões de assombro, beleza e expectativas aventureiras que são conduzidas para mim por certas vistas (cênicas, arquiteturais, atmosféricas etc), ideias, ocorrências, e imagens encontradas na arte e literatura. Eu escolho histórias de horror porque elas servem melhor minha inclinação - um dos meus mais fortes e mais persistentes desejos sendo alcançar momentaneamente a ilusão de alguma estranha suspensão ou violação da irritante limitação do tempo, espaço e lei natural que eternamente nos aprisionam e frustram nossa curiosidade sobre o infinito espaço cósmico além do raio da nossa visão e análise. (LOVECRAFT, 1933).

De certa forma, podemos ver a mitologia lovecraftiana não apenas representada em diversos produtos ciberculturais, mas também como um espelho da própria cibercultura. Ambos desenvolvem uma nova forma de religiosidade e deixam no ar a ideia do extermínio da raça humana pelos seus novos deuses (sejam monstros ou máquinas) enquanto continuamos maravilhados com a potência que esses deuses possuem e o desconhecido que representam.

Yuri Garcia é doutorando em Comunicação Social pelo Programa de Pós Graduação em Comunicação da Universidade do Estado do Rio de janeiro (UERJ). É autor do livro "Drácula: o vampiro camaleônico" (2014).

yurigpk@hotmail.com

5 Divindade, espiritual.

16 Hans Ulrich Gumbretch desenvolve o conceito de "Stimmung" exemplificando melhor a ideia das sensações e ambiências causadas pela leitura (e que exemplifica perfeitamente a sensação de ler Lovecraft). Infelizmente, a palavra "Stimmung" em alemão não possui uma tradução que consiga trazer todas as possibilidades que o autor procura passar. Entretanto o texto "Reading for the Stimmung? About the Ontology of Literature Today" de Gumbretch apresenta uma explicação detalhada de tal conceito. 


\section{Referências}

ANDERSON, C. A cauda longa. Rio de Janeiro: Elsevier Editora, 2006.

BEAL, T. K. Religion and its monsters. New York: Routledge, 2002.

BLOOM, H. A Angústia da influência. Rio de Janeiro: Imago, 2002.

BOLTER, J. D.; GRUSIN, R. Remediation: Understanding New Media. Cambridge: The MIT Press, 2000.

CARROLL, N. The Philosophy of Horror. New York: Routledge, Chapman and Hall, Inc., 1990.

DELEUZE, G. Crítica e Clínica. São Paulo: Ed. 34, 1997

; GUATTARI, F. Mil Platôs: Capitalismo e Esquizofrenia. Vol 1. Rio de Janeiro: Ed. 34, 1995.

Mil Platôs: Capitalismo e Esquizofrenia. Vol 4. São Paulo: Ed. 34, 1997.

ENNE, A. L. S. O conceito de rede e as sociedades contemporâneas. Comunicação e informação. Goiânia, V 7, n 2, jul/dez 2004. p. 264-273.

FELINTO, E. A religião das máquinas: ensaios sobre o imaginário da cibercultura. Porto Alegre: Sulina, 2005.

. Passeando no Labirinto: Ensaios sobre as Tecnologias e as Materialidades da Comunicação. Porto Alegre: EDIPUCRS, 2006.

All Hail the Great Cthulhu: A Segunda Vida de H. P. Lovecraft, Filósofo Especulativo e PósHumanista. In: MONTEIRO, M. C.; GIUCCI, G.; PINHO, D. (Org.). Eros, tecnologia, transhumanismo: Figurações Cultuais Contemporâneas. Rio de Janeiro: Caetés, 2015, p. 121-142.

Paulus, 2012.

; SANTAELLA, L. O explorador de abismos: Vilém Flusser e o pós-humanismo. São Paulo:

GIGER; H. R. Necronomicon. Los Angeles: Morpheus Internacional, 1992.

GUMBRECHT, H. U. Reading for the Stimmung? About the Ontology of Literature Today. Boundary 2. Durham, Fall 2008, 35(3), p. 213-221.

HOUELLEBECQ, M. H. P. Lovecraft: Against the World, Against Life. San Francisco: Believer Books (Division of McSweeney's Books), 2005.

JANCOVICH, M.; et al. Defining Cult Movies: The Cultural Politics of Oppositional Tastes. Manchester: Manchester University Press, 2003.

JOSHI, S. T. A Dreamer and a Visionary: H. P. Lovecraft in his time. Liverpool: Liverpool University Press, 2001.

I I Am Providence: The Life and Times of H. P. Lovecraft. New York: Hippocampus Press, 2010.

KURTZ, G. B. O Culto de Cthulhu na Cibercultura: as ressignificações do conto de H. P. Lovecraft no Facebook. Revista Abusões. Rio de Janeiro, n.4, v.4, 2017. p. 433-475.

KUTRIEH, M. G., The Cosmology of H. P. Lovecraft. Bulletin of the Faculty of Humanities and Social Sciences, Qatar University, No. 8, 1985. p. 37-49.

LATOUR, B. Reagregando o social: Uma introdução à Teoria do Ator-Rede. Salvador: Edufba; São Paulo: Edusc, 2012.

LOVECRAFT, H. P. Supernatural Horror in Literature. 1927. Obtido em domínio público em: http:// www.hplovecraft.com/writings/texts/essays/shil.aspx 
. Notes on Writing Weird Fiction. 1933. Obtido em domínio public em: http://www.hplovecraft. com/writings/texts/essays/nwwf.aspx

The Complete Works of H. P. Lovecraft. CthulhuChick.com, 2011. (Obtido em domínio público em: http://arkhamarchivist.com/free-complete-lovecraft-ebook-nook-kindle/)

PRICE, E. H. Through the Gates of the Silver Key. The University of Adelaide Library (eBooks@ Adelaide), 2014

LUDUEÑA ROMANDINI, F. H. P. Lovecraft: a disjunção no ser. Desterro, Florianópolis: Cultura e Barbárie, 2013.

MAPA, R. "Introdução Darkside" . In: LOVECRAFT, H. P.. H. P. Lovecraft: medo clássico volume 1. Rio de Janeiro: DarkSide Books, 2017.

MESSIAS, J. A construção da figura do herói nos mangás e comics: uma análise comparativa entre samurais e super-heróis. Rio de Janeiro: UERJ, PPGCom, 2012. Dissertação (Mestrado - Programa de Pós-Graduação em Comunicação). Universidade do Estado do Rio de Janeiro.

MISCHE, A. Relational Sociology, Culture and Agency. In: SCOTT, J. \& CARRINGTON, P.. Sage Handbook of Social Network Analysis. Los Angeles: Sage Publications, 2011.

MITCHELL, J. C. Social Networks. Annual Review of Anthropology. Palo Alto, Vol 3, 1974. p.279-299.

PEREIRA, V. A. Estendendo McLuhan: da Aldeia à Teia Global - Comunicação, Memória e Tecnologia. Porto Alegre: Sulina, 2011.

REGIS, F. Do corpo monstruoso ao mito do cyborg: os processos de construção de identidade e diferença no ocidente. In: VIII Encontro da Compós - Associação Nacional dos Programas de PósGraduação em Comunicação, 1999, Belo Horizonte. Anais... 8o. Encontro Anual da Compós. Belo Horizonte: Compós - UFMG, 1999. v. 1.

; MESSIAS, J. Comunicação, Tecnologia e Cognição: rearticulando homem, mundo e pensamento. In: REGIS et al. (org.) Tecnologias de comunicação e cognição. Porto Alegre: Editora Sulina, 2012.

REIS FILHO, L. H. P. Lovecraft no cinema dos anos 70 e 80: da inadaptabilidade aos novos reinos imaginativos. Revista Abusões. Rio de Janeiro n.4, v.4, 2017. p. 356-387.

SCOTUZZI, N. S.; ROSSI, A. D. Do inominável ao cientificamente explícito: monstros lovecraftianos. Revista Abusões. Rio de Janeiro, n.4, v.4, 2017. p. 69-99.

SIMONDON, G. On the Mode of Existence of Technical Objects. University of Western Ontario, 1980.

THACKER, E. In the Dust of This Planet: Horror and Philosophy, Volume 1. Alresford: John Hunt Publishing, 2011.

TICON, F.; MAPA, R. "Lovecraft e a Cultura Pop". In: LOVECRAFT, H. P. H. P. Lovecraft: medo clássico volume 1. Rio de Janeiro: DarkSide Books, 2017.

TUCHERMAN, I. Breve história do corpo e de seus monstros. Lisboa: Editora Vega, 1999.

VASCONCELOS, S. G. Dez lições sobre o romance inglês no século XVII. São Paulo: Boitempo Editorial, 2002. 